\title{
Forecasting of Economic Efficiency of the City-Forming Enterprise in the Monotown
}

\author{
Ph.D. Candidate Oksana Gurieva (Chelyabinsk State University, Russia) \\ Prof. Dr. Viktor Barhatov (Chelyabinsk State University, Russia)
}

\begin{abstract}
Research objective is development of the forecast of scenario conditions of increase of economic efficiency of the city-forming enterprise of the monotown for further social and economic development of the region for 2014-2016. For achievement of a goal a number of tasks is solved: consideration of theoretical prerequisites to concept economic efficiency; research of features of economic efficiency of the city-forming enterprise in the monotown; choice of a method of forecasting; forecasting of economic efficiency of the city-forming enterprise. When carrying out research scenario approaches and expert methods of forecasting are used. The main versions of the forecast - option 1 (conservative), option 2 (moderate and optimistical) and option 3 (forced) - are developed on the basis of a uniform hypothesis of external conditions and differ with models of behavior of the enterprises of the monotown, and as with prospects of increase of their efficiency. It is established that at realization of all versions of the forecast economic efficiency of the city-forming enterprise of the monotown increases. However quality of this increase in considered scenarios of the forecast of social and economic development of the region variously. As the most acceptable the moderate and optimistical option is recognized, so at its realization economic efficiency will increase on the average 0,7 items above, than in option 1 . The moderate and optimistical option is more focused on innovations, assumes carrying out transformations in development of the human capital and science, and also active modernization of the enterprise.
\end{abstract}

\section{Introduction}

For achievement of a goal a number of tasks is solved: consideration of theoretical prerequisites to concept economic efficiency; research of features of economic efficiency of the city-forming enterprise in the monotown; choice of a method of forecasting; forecasting of economic efficiency of the city-forming enterprise. When carrying out research scenario approaches and expert methods of forecasting are used. The main versions of the forecast - option 1 (conservative), option 2 (moderate and optimistical) and option 3 (forced) - are developed on the basis of a uniform hypothesis of external conditions and differ with models of behavior of the enterprises of the monotown, and as with prospects of increase of their efficiency. It is established that at realization of all versions of the forecast economic efficiency of the city-forming enterprise of the monotown increases. However quality of this increase in considered scenarios of the forecast of social and economic development of the region variously. As the most acceptable the moderate and optimistical option is recognized, so at its realization economic efficiency will increase on the average 0,7 items above, than in option 1 . The moderate and optimistical option is more focused on innovations, assumes carrying out transformations in development of the human capital and science, and also active modernization of the enterprise.

\section{Consideration of Theoretical Prerequisites to Concept Economic Efficiency of the City-Forming Enterprise}

We will consider approaches on problems of economic efficiency of the city-forming enterprises stated in works of the Russian and foreign scientists in the field of economy. The majority of scientists differently treat this category, attaching crucial significance to these or those forms of efficiency. At the initial stage of development of political economy there were approaches to connect efficiency not with the concrete enterprise, and with this or that branch of national economy. So representatives of mercantilists considered efficiency of foreign trade since efficiency of development of the state contacted its balance of trade balance. The states sought to develop during this era export-import transactions bringing in the additional income. Representatives physiocrates connected economic efficiency with agriculture, only agriculture, according to doctrines physiocrates is that branch where the pure product, a source of public wealth is created. Representatives of classical school of the theory of cost and distribution of economic efficiency connected with the industry and considered production efficiency on the basis of made work. Representatives of historical school connected efficiency of national productive forces with category of a land rent. Representatives of classical institutionalism connected efficiency with institutes - forms and borders of activity of people in the course of corporate activity. In works of economists of a neoclassical naprvleniye problems of efficiency of corporations were considered connected with distribution of resources for economic activity in economy. The Russian economic theory considered economic efficiency from the point of view of profitability of production. During research of macroeconomic and microeconomic efficiency of the city-forming enterprise we investigated its main feature. It includes resource, economic, institutional and social efficiency. Resource efficiency is understood as degree of intensity of use of resources of the city-forming enterprise which change doesn't rely on the price of made 
production or used factors of production. Economic efficiency considers the solvent demand shown by this or that market according to usefulness of result of activity (product) of the city-forming enterprise, and the market prices connected with it. Institutional efficiency is characteristic for conditions of transformational economy in which the great value is got by the institutional aspects of activity reflecting the purposes of institutional agencies, connected with the enterprise of public sector. Institutional efficiency expands the horizon of an assessment of integrated efficiency to borders of the period of completion of the main institutional transformations in a branch, market and regional environment of the city-forming enterprise. Social efficiency appeared as result of activity of the city-forming enterprise in the field of the solution of social problems in society. It is expressed in such indicators, as level and quality of life of the population, including - an education level, health care, social security, development of science and culture, alignment of levels of the income of different segments of the population and others. The category "economic efficiency" is considered as result of a ratio of gained income and the incurred expenses, as ability of system to reach the objectives determined by functions of the system. At a microeconomic level economic efficiency is shown at the enterprises as profitability of activity. For the city-forming enterprise such approach is narrow. As, besides economic, it carries out also social and other functions. (Barkhatov V. I. ve Barkhatov I.V, 2002).

\section{Forecasting of Economic Efficiency of the City-Forming Enterprise in the Monotown}

As economic efficiency is a ratio of useful result and expenses for further forecasting of efficiency of the enterprise it is necessary to reveal interrelations of volume of output, expenses and arrived that it is possible to make by means of economic-mathematical modeling. Economic-mathematical modeling allows to define quantitative expression of interrelations between indicators the volume of output, expenses and profit and the factors influencing their size. Creation of economic-mathematical model of interrelation of volume of output, expenses and profit consists of several stages: Economic problem definition and the purpose of its decision studying of dynamics of indicators in a definite time (year) and identification of the factors influencing this dynamics. Calculation of functional dependence of volume of output, expenses and profit on defining factors - a statistical assessment of initial information regarding its compliance to requirements of the carried-out analysis; Development of various versions of the forecast of indicators. (Barkhatov V. I. ve Pletnyov D. A., 2003)

The analysis and assessment of possible dynamics of indicators in the future - stay and a statistical assessment of the equation of communication between productive and factorial signs. Choice of optimum option, i.e. adoption of the administrative decision.

When developing model of volume of output, expenses and profit initial information has to conform to the following requirements:

The variation of productive and factorial signs has to be observed visually;

The statistical group has to be uniform in the qualitative and quantitative relation;

The number of objects of supervision has to be more number of factorial signs;

Factorial signs have to be closely connected with a productive sign, but shouldn't be closely connected among themselves. The purpose of development of model of volume of output, expenses and profit consists in identification of interrelation and disclosure of nature of communication and extent of influence of factorial signs on the productive. The model joins only the major (defining) factors. Check of validity of model carry out in practice. Thus imposing appearance of model, i.e. duration of nablyukdeniye for the studied period matters. The process of forecasting leaning on statistical methods, breaks up to two stages. The first stage - inductive. At this stage synthesis of data for more or less long period of time and representation of the corresponding statistical regularities in the form of model is carried out: equation of dependence on one or several arguments. The second stage - deductive. At this stage the forecast is carried out and on the basis of the found general regularity private expected value of a predicted sign is defined. The economic-mathematical model can be based on the functional or correlation analysis are effective methods which allow to analyze considerable volumes of information with a research objective of probable interrelation of two or more variables. (Kokorina, 2007)

Functional communication is a communication at which all ratios are established in the determined form that is it is assumed that if two variables interconnected, answer any preset value of one variable only one value of the second. For functional communication that changes of a productive sign are entirely caused by action of a factorial sign is characteristic. This communication is represented by means of mathematical model and is expressed by the equation:

$$
y=f(x)
$$

where $\mathrm{y}$ - the corresponding indicator;

$\mathrm{f}(\mathrm{x})$ - the functional communication determined by an indicator $\mathrm{x}$. 
Feature of functional communication is that it is shown with an identical force for each unit of population which is studied. Therefore, having established when studying any unit of population this or that regularity, it can be extended both to each unit, and to all set. Correlation communication is a communication where influence of separate factors is shown only as a tendency at mass supervision of actual data. Data which gather for carrying out the regression analysis, usually represent "historical" data that is figures which show value of any of factors in any of the previous periods of time or geographical areas. They are used for receiving estimates of coefficients of regression and definition of degree of compliance of model of the corresponding reality to changes of a productive sign. It is possible to characterize dependence of a variation of a productive sign on a sign factor variation by means of exponents of narrowness of communication. Knowing indicators of narrowness of correlation communication, it is possible to solve the following groups of questions: The first question - to answer a question of need of studying of this communication between signs and expediency of its practical application. The second question - comparing indicators of narrowness of communication for various situations, it is possible for a sudiya, about degree of distinctions in its manifestation for specific conditions. The third question - comparing indicators of narrowness of communication of a productive sign with various factors, it is possible to reveal those factors which in these specific conditions are rekshayushchy and mainly influence formation of size of a productive sign. The most perfect exponent of narrowness of communication is the linear coefficient of correlation. At calculation of this indicator signs of deviations of individual values of a sign from average, and the size of such deviations are considered. However it is impossible to compare among themselves received absolute values as signs can be expressed in different units, and in the presence of the same units of measure averages can be various in size. In this regard the deviations expressed in relative sizes, i.e. in shares of an average quadratic deviation can be subject to comparison.

The mean square deviation is determined by a formula:

$$
\bar{Z}=\sqrt{\frac{\sum(y-y x)^{2}}{n}},
$$

where $\bar{Z}$ - a mean square deviation;

у и ух — the actual and settlement sum arrived respectively;

$\mathrm{n}$ - number of cases of supervision.

The coefficient of a variation represents percentage of a mean square deviation to the arithmetic-mean size of a reporting indicator (profit).

$$
K_{s}=\frac{ \pm \bar{Z}}{\bar{y}} \times 100
$$

where $\bar{Z}$ - a mean square deviation;

$\mathrm{y}$ - the arithmetic-mean size of profit, thousand rubles.

If the coefficient of a variation shows that the deviation of settlement pokakzatel from the actual makes insignificant size, dо вы $\neg$ вод that this model can be used for planning of financial resources. Studying of correlation dependences is based on research of such communications between variables at which values of one variable "on the average" change depending on what values accepts other variable considered as the reason in relation to a dependent variable. Action of this reason is carried out in the conditions of difficult interaction of various factors owing to what manifestation of regularity is darkened by influence of accidents. Calculating average values of a productive sign for this group of values of a sign factor, we partly eliminiruy influence of accidents. Calculating parameters of the theoretical communication line, their further elimination is made and $\mathrm{Y}$ change with change of a factor by $X$ turns out unambiguous (in a form). Thus, the expected model of interrelation of volume of output, expenses and profit is the action program of the organization establishing interrelation of volume of output, expenses and profit for increase of economic efficiency of the city-forming enterprise. For creation of model we will group indicators of volume of output, expenses and arrived to JSC Shadrinsk Automodular Plant - the city-forming enterprise of the city of Shadrinsk for 2011-2013 (Table 1).

\begin{tabular}{|c|c|c|c|}
\hline Period & Output volume & Costs & Profit on sales \\
\hline 2011 & 272421 & 760752 & -488331 \\
\hline 2012 & 391333 & 1185933 & -794600 \\
\hline 2013 & 483670 & 430009 & 53661 \\
\hline
\end{tabular}

Table 1 - Group of indicators for expected model of interrelation of volume of output, expenses also arrived to JSC Shadrinsk Automodular Plant Source: financial statements of JSC Shadrinsk Automodular Plant

We will construct economic-mathematical model:

We will enter designations: 
$\mathrm{Y}$ - Profit on sales;

X1 - Output volume;

$\mathrm{X} 2$ - Costs,

The model of communication includes two parameters therefore the linear equation has an appearance:

$$
\bar{y}=a+b_{1} x_{1}+b_{2} x_{2}
$$

System of the normal equations for finding of parameters the following:

$$
\left\{\begin{array}{l}
n a+b_{1} \sum x_{1}+b_{2} \sum x_{2}=\sum y \\
a \sum x_{1}+b_{1} \sum x_{1}^{2}+b_{2} \sum x_{2} \cdot x_{1}=\sum y x_{1} \\
a \sum x_{2}+b_{1} \sum x_{1} \cdot x_{2}+b_{2} \sum x_{2}^{2}=\sum y x_{2}
\end{array}\right.
$$

\begin{tabular}{|l|l|l|l|l|l|l|l|l|}
\hline$№$ & $\mathrm{Y}$ & $\mathrm{X} 1$ & $\mathrm{X} 2$ & $\mathrm{X}_{1}{ }^{2}$ & $\mathrm{X}_{1} \mathrm{X}_{2}$ & $\mathrm{YX}$ & $\mathrm{X}_{2}{ }^{2}$ & $\mathrm{Y} \mathrm{X}_{2}$ \\
\hline 1 & $-488,331$ & 272,421 & 760,752 & 74213,201 & 207244,821 & $-133031,619$ & 578743,606 & $-371498,785$ \\
\hline 2 & $-794,600$ & 391,333 & 1185,933 & 153141,517 & 464094,719 & $-310953,202$ & 1406437,080 & $-942342,362$ \\
\hline 3 & 53,661 & 483,670 & 430,009 & 233936,669 & 207982,453 & 25954,216 & 184907,740 & 23074,713 \\
\hline$\sum$ & $-1229,270$ & 1147,424 & 2376,694 & 387078,186 & 672077,172 & $-284998,986$ & 1591344,821 & $-919267,649$ \\
\hline Average & $-614,635$ & 573,712 & 1188,347 & 193539,093 & 336038,586 & $-142499,493$ & 795672,410 & $-459633,824$ \\
\hline
\end{tabular}

Table 2 - The calculation table for determination of parameters of the equation of regression Source: financial statements of JSC Shadrinsk Automodular Plant

$$
\left\{\begin{array}{l}
3 \cdot a+1147,424 \cdot b_{1}+2376,694 \cdot b_{2}=-1229,270 \\
1147,424 \cdot a+387078,186 \cdot b_{1}+672077,172 \cdot b_{2}=-284998,986 \\
2376,694 \cdot a+672077,172 \cdot b_{1}+1591344,821 \cdot b_{2}=-919267,649
\end{array}\right.
$$

The decision of system of the equations gives the following model of interrelation of volume of output, expenses and profit:

$$
\widehat{y}=\mathbf{O}+\mathbf{1} x_{1}-\mathbf{1} x_{2}
$$

For comparison of a role of separate factors in model of interrelation of volume of output, expenses and profit elasticity coefficients are defined. Calculation of averages is made in Table 2.

Calculation of coefficients of elasticity:

for output volume: $\quad \ni_{1}=b_{1} \cdot \frac{\bar{x}_{1}}{\bar{y}}=1 \cdot \frac{573,712}{614,635}=0,9334$

for expenses: $\Im_{2}=b_{2} \cdot \frac{\bar{x}_{2}}{\bar{y}}=-1 \cdot \frac{1188,347}{614,635}=1,9334$

Therefore, at increase in volume of output at $1 \%$ the profit on sales will increase by $0,9334 \%$. The increase in expenses at $1 \%$ will reduce profit on sales by $1,9334 \%$.

Calculations of interrelation of volume of output, expenses and profit for JSC Shadrinsk Automodular Plant provide three options. The first option provides application of established price of production and indicators of sales volume and expenses of 2013 (conservative). The second option provides increase in the price of production at $10 \%$ without change of sales volume and expenses (moderate and optimistical). The third option provides reduction of the price of production by $10 \%$ without change of sales volume and expenses ((forced).

As a result of the carried-out calculations it is received that at the change in price and at invariable indicators of volume and size of expenses the marginal income and size of profit on production realization changes. The carried-out calculations showed that JSC Shadrinsk Automodular Plant will get the greatest profit at sale of 195028 units of production at the change in price for $10 \%$. Thus, by results of an assessment of indicators of interrelation of volume of output, expenses and profit it is possible to draw the following conclusion. In model of interrelation of volume of output, expenses and profit the increase in volume of release in 2014 for $10 \%$ is possible due to increase of the price for $10 \%$ and application to calculation of the price of valuable approach.

Therefore, level of efficiency of the developed expected model of interrelation of volume of output, expenses and profit the high. The expected model has probabilistic character, and during its formulation it is impossible to expect all opportunities which will appear when developing the program of concrete actions. 


\section{Acknowledgement}

The publication was prepared as part of a research project supported by RSF (application \# 14-18-02508).

\section{References}

- Barkhatov V. I. and Barkhatov I.V, 2002. «Mobilization of the financial capital in transformed economy»: Monograph. - Chelyabinsk.

- Barkhatov V. I. and Pletnyov D. A., 2003. "Institutional economic efficiency of corporation: contents, criteria, indicators and factors". Scientific notes of the Tambov regional office of free economic society of Russia. Volume 5 - Tambov. P. 36-46.

- Kokorina, 2007. "Efficiency of public sector of economy", the collection of materials of the All-Russian scientific and practical conference "Tendencies and Current State of History, Economy and Right" Shadrinsk, P. 351-357 